Felipe Monteleone Vieceli

\title{
Fatores de transcrição no desenvolvimento inicial do tubo neural posterior
}

Tese apresentada ao Departamento de Biologia Celular e do Desenvolvimento do Instituto de Ciências Biomédicas da Universidade de São Paulo, para obtenção do Título de Doutor em Ciências.

Área de concentração: Biologia Celular e Tecidual

Orientação: Profa. Dra. Chao Yun Irene Yan

Versão original 


\section{RESUMO}

Vieceli FM. Fatores de transcrição no desenvolvimento inicial do tubo neural posterior. [Tese (Doutorado em Biologia Celular e Tecidual)]. São Paulo: Instituto de Ciências Biomédicas, Universidade de São Paulo; 2015.

O início da neurogênese e diferenciação neural no sistema nervoso do embrião é controlado pela expressão orquestrada de fatores de transcrição que regulam a expressão gênica. A caracterização de novos fatores de transcrição importantes nestes processos é fundamental para o entendimento completo dos mecanismos responsáveis pela formação de neurônios. Um dos enfoques da nossa pesquisa foi a proteína Scratch2, pertencente à superfamília Snail de fatores de transcrição do tipo zinc-finger. Estudos prévios realizados em vertebrados mostraram que Scratch2 promove a saída do ciclo celular e sobrevivência de precursores neurais no tubo neural posterior de zebrafish e controla a migração correta de neurônios no córtex de camundongo em formação. No presente trabalho, nós usamos o tubo neural posterior do embrião de galinha para estudar a função de Scratch2. Nossos resultados indicam que nesta estrutura Scratch2 é expresso mais intensamente em células recém-saídas do ciclo celular, muitas das quais expressam também os fatores de transcrição proneurais do tipo bHLH Neurogenina2 e NeuroM, que promovem a indução e o estabelecimento da diferenciação neural. Estas observações sugerem que Scratch2 possui uma função importante durante o início da diferenciação neural, sendo consistentes com as funções previamente descritas em outras espécies. Para estudar os genes regulados por Scratch2, superexpressamos formas alteradas de Scrt2 no tubo neural posterior com eletroporação in ovo e analisamos os fenótipos transcricionais com RNA-Seq. Nossas análises identificaram alguns genes com variações de expressão muito sutis, que não foram validados com qPCR. Acreditamos que esta discrepância seja gerada por causas metodológicas. Primeiramente, a eletroporação gera um tecido em mosaico e, como consequência, as amostras usadas eram intrinsicamente heterogêneas quanto aos níveis de transfecção. Concluímos que os tecidos eletroporados com eficiência baixa não geram amostras ideais para RNA-Seq. Por fim, também apresentamos aqui uma caracterização transcriptômica do tubo neural posterior de embriões com $36 \mathrm{~h}$ (HH18) ou 6 dias de desenvolvimento, englobando um período de transição entre o início da neurogênese e o estabelecimento da diferenciação neural. A comparação cruzada entre as amostras revelou genes enriquecidos no tecido neural e permitiu a identificação de potenciais novos reguladores e módulos de coexpressão associados à diferenciação neural. Importantemente, estes experimentos produziram uma rica base de dados transcriptômicos para futuras investigações do desenvolvimento da medula espinhal.

Palavras-chave: Desenvolvimento do sistema nervoso. Neurogênese. Diferenciação neural. Scratch. Fatores de transcrição. RNA-Seq. 


\begin{abstract}
Vieceli FM. Transcription factors in the early posterior neural tube. [Ph. D. Thesis (Cell and Tissue Biology)]. São Paulo: Instituto de Ciências Biomédicas, Universidade de São Paulo; 2015.

The onset of neurogenesis and neural differentiation in the embryonic nervous system is controlled by the coordinated expression of transcription factors that determine gene expression dynamics. Identification of novel transcription factors capable of regulating these processes is essential for our understanding of the mechanisms underlying neuronal differentiation. One of the focuses of our research was the protein Scratch2, which is a member of the Snail superfamily of zinc-finger transcription factors. Previous research in vertebrate model systems has shown that Scratch 2 promotes cell cycle exit and survival in the posterior neural tube of zebrafish and controls neuronal migration in the murine cortex. Here, we used the chick embryonic spinal cord to investigate further the role of Scratch2. Our results indicate that, in the chick, Scratch2 expression is concentrated in cells that recently exited the mitotic cycle, coinciding with the expression domain of the proneural bHLH transcription factors Neurogenin2 and NeuroM, which promote and maintain the onset of neural differentiation. These results suggest that Scratch 2 plays a relevant role in the early stages of differentiation, being consistent with data obtained in other animal models. To identify potential gene targets of Scratch2, we overexpressed altered forms of Scratch2 with in ovo electroporation and assessed the transcriptomic phenotypes using RNA-Seq. Our results revealed some weakly altered genes that were not confirmed in qPCR assays. We believe that this divergence has methodological reasons. First, electroporation of the neural tube generates a mosaic pattern and, consequently, the samples used for the RNA-Seq analysis were heterogeneous in their levels of transfection. Thus, we conclude that tissues electroporated with low efficiency do not produce ideal samples for RNA-Seq studies. Finally, we also present here the transcriptomic profiles of the neural tube from $\mathrm{HH} 18$ and $\mathrm{HH} 29$ (E6) embryos, encompassing a period of transition from the onset of neurogenesis to a predominantly differentiating cell population. Through cross-sample comparisons, we identified genes enriched in the neural tube and analyzed their temporal expression profiles and correlation. These results allowed us to identify novel regulators and modules of expression associated to neural differentiation. Importantly, this work generated a transcriptomic database that will contribute towards future research on the spinal cord development.
\end{abstract}

Keywords: Nervous system development. Neurogenesis. Neural differentiation. Scratch. Transcription factors. RNA-Seq. 


\section{CAPÍTULO 1 - INTRODUÇÃO GERAL}

\subsection{Neurogênese e diferenciação neural no sistema nervoso embrionário}

O sistema nervoso de vertebrados se forma a partir da placa neural, uma estrutura ectodérmica especificada imediatamente após a gastrulação. A porção central da placa neural dá origem ao sistema nervoso central (SNC), enquanto em sua periferia se forma a crista neural, uma estrutura transiente composta por células migratórias que, entre outros derivados, formam grande parte do sistema nervoso periférico (SNP). O passo seguinte é a neurulação, um processo morfogenético no qual a placa neural se dobra sobre ela mesma para formar o tubo neural, cujo lúmen dará origem ao ventrículo. A porção mais rostral do tubo formará as estruturas cefálicas do SNC, enquanto a medula espinhal se forma a partir das porções truncal e caudal do tubo. Após a neurulação, a crista neural fica localizada dorsalmente ao tubo neural, sendo este o ponto de partida destas células, que migram para colonizar locais específicos, onde se diferenciam em uma gama de tipos celulares (Gilbert, 2010; Jacobson, 1991; Le Douarin, Kalcheim; 1999).

O tubo neural recém-fechado é formado por células-tronco neurais em estado proliferativo, que se organizam radialmente em um neuroepitélio polarizado (Fig. 1; Hollyday, 2001). Em seu polo apical, os progenitores neurais interagem por meio de junções aderentes e delimitam a cavidade ventricular, enquanto interações entre integrinas e lamininas aderem sua porção basal à matriz extracelular subpial, que envolve externamente o tubo neural (Rousso et al., 2012). Essa população de células proliferativas é sempre mantida ao redor do ventrículo, formando a zona ventricular, e dará origem aos diferentes subtipos de neurônios e glia ao longo do desenvolvimento do SNC. As junções aderentes formam pontos de contato entre os progenitores em proliferação e também com a superfície do ventrículo, além de ancorar proteínas sinalizadoras importantes para a manutenção do estado proliferativo destas células (Stepniak et al., 2009; Zhang et al., 2010). Desta forma, acredita-se que as junções aderentes são essenciais para o estabelecimento de um nicho para células-tronco neurais (Rousso et al., 2012). Por exemplo, as junções aderentes do neuroepitélio possuem cateninas, entre as quais beta-catenina, responsável por mediar o efeito proliferativo da via do Wnt nestas células, e caderinas, que, além de serem responsáveis pela adesão célula-célula, podem atuar como fatores anti-apoptóticos (Carmeliet et al., 1999; Farkas, Huttner, 2008). 


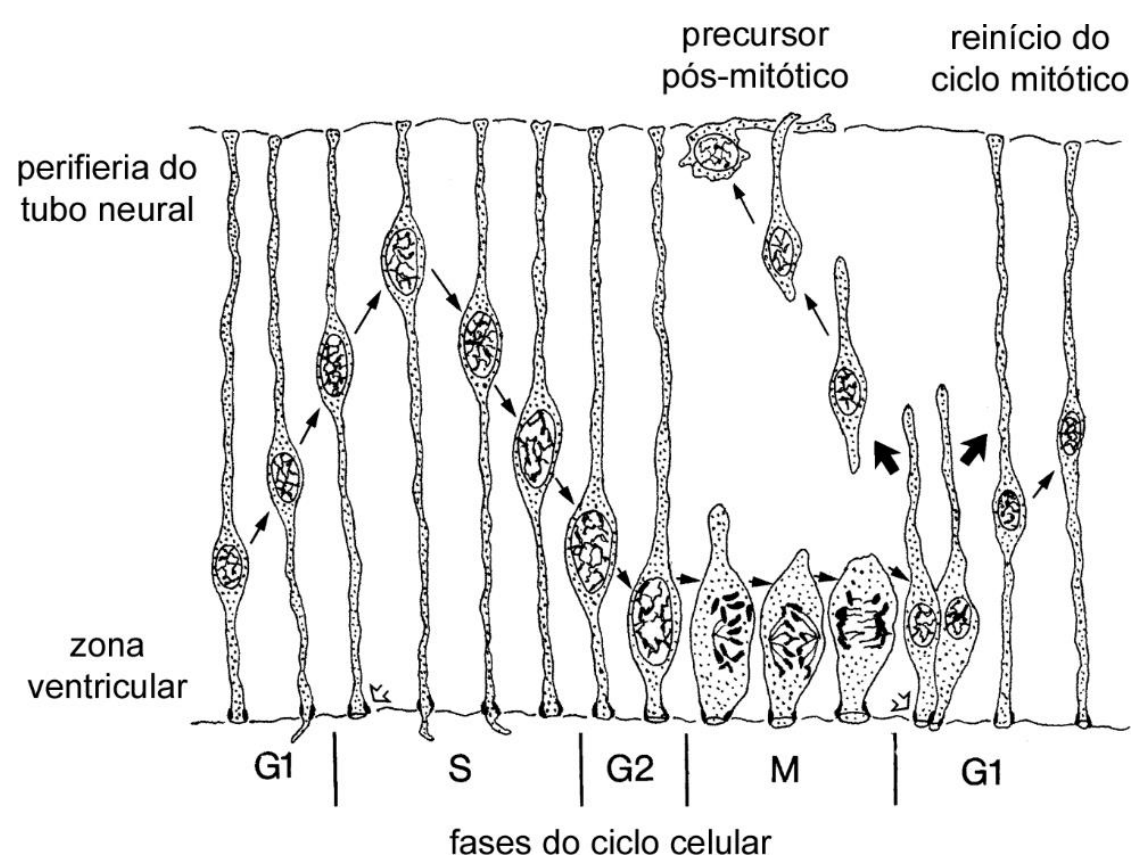

Figura 1. Organização do neuroepitélio e divisão assimétrica de progenitores neurais. Durante o ciclo celular, os núcleos progenitores em proliferação migram ao longo eixo próximo-distal, de forma que a síntese de DNA (fase S) ocorre na porção basal da célula e a mitose se dá na porção apical, associada à zona ventricular. Após a divisão assimétrica, o jovem neurônio migra para a periferia do tubo, enquanto o novo progenitor retoma o posicionamento original e reinicia o ciclo celular. Adaptado de Hollyday (2001) baseado em Jacobson (1991).

A neurogênese é o processo de nascimento de neurônios, onde um progenitor neural se divide assimetricamente para gerar um novo progenitor mitoticamente ativo e um precursor neural pós-mitótico, que então inicia o processo de diferenciação para se tornar um jovem neurônio (Fig. 1; Hollyday, 2001). Isto possibilita a formação de neurônios e, ao mesmo tempo, a renovação da população de progenitores ao longo do desenvolvimento. Um mecanismo conservado neste processo em vertebrados e invertebrados é a atuação de Notch1 na manutenção do estado proliferativo de progenitores neurais por meio da repressão de fatores de transcrição proneurais, capazes de iniciar a diferenciação neural (Bertrand et al., 2002; Ross et al., 2003). Notch1 é um receptor de membrana que, ao ser ativado por seus ligantes, como a proteína de membrana Delta1, tem seu domínio intracelular liberado para formar um complexo com RBP-J que ativa a transcrição dos fatores de transcrição do tipo bHLH (basic Helix-Loop-Helix) da família Hes (Hairy and Enhancer of Split) (Honjo, 1996; Ohtsuka et al., 1999). Hes1 reprime a expressão do fator de transcrição proneural Ngn2 (Neurogenina2) e também de Delta1. Mesmo ativada, a expressão Hes1 se dá de maneira oscilatória nos progenitores neurais, consequência de um feedback negativo causado, em conjunto, por sua habilidade de se auto reprimir e pela alta instabilidade de seu mRNA e 
proteína (Hirata et al., 2002; Takebayashi et al., 1994). Isto, por sua vez, faz com que a expressão de Ngn2 e Delta1 também oscilem, o que pode ser importante para a ativação mútua de Notch1 por níveis baixos de Delta1 nas membranas das células vizinhas e consequente manutenção do estado proliferativo (Shimojo et al., 2008).

No neurônio recém-nascido, Notch1 deixa de ser expresso e a expressão de Ngn2 e Delta1 em níveis altos é estabelecida. Acredita-se que uma herança desigual de Numb, uma proteína expressa assimetricamente em progenitores neurais capaz de degradar Notch em invertebrados, seja importante para esse passo também em vertebrados (Cayouette, Raff, 2002; Jafar-Nejad et al., 2002; Rousso et al., 2012). Agora com a expressão estabilizada, Ngn2 inicia a diferenciação neural, em parte reprimindo completamente a expressão de Sox1-3, fatores de transcrição que atuam para manter o estado indiferenciado (Bylund et al., 2003). Além disso, no córtex embrionário, Ngn2 regula a migração correta dos precursores neurais para regiões mais superficiais (Heng et al., 2008). Outros fatores bHLH proneurais que atuam apenas nos precursores pós-mitóticos, tais como NeuroM (NEUROD4), expresso imediatamente após a saída do ciclo celular, e NeuroD (NEUROD1), um fator expresso mais tardiamente capaz de promover a saída do ciclo celular e a diferenciação neural, também têm sua expressão ativada com o progresso da diferenciação (Lee et al., 1995; Roztocil et al., 1997).

Após deixar o ciclo celular e durante sua diferenciação inicial, os precursores neurais migram para a periferia do tubo, onde ocorre a diferenciação tardia. Para que isso ocorra, estas células precisam desmontar suas junções aderentes, que as mantêm presas à zona ventricular. Dentro da família das caderinas, a que tem expressão mais significativa no tubo neural é a $\mathrm{N}$-caderina, que progressivamente substitui a E-caderina expressa no ectoderme pré-neural (Dady et al., 2012; Rogers et al., 2013). Estudos realizados na medula espinhal do embrião de galinha mostraram que o fator de transcrição FOXP4 reprime diretamente a expressão de $\mathrm{N}$-caderina para inibir a formação de junções aderentes, permitindo assim o destacamento dos precursores neurais (Rousso et al., 2012). Apesar de ter sua expressão reduzida drasticamente logo após a neurulação, evidências obtidas no córtex do embrião de camundongo sugerem que a expressão de E-caderina precisa ser ativamente reprimida pelos fatores de transcrição Scrt (Scratch) para permitir a migração correta dos precursores neurais para camadas externas (Itoh et al., 2013; Paul et al., 2014). Interessantemente, a inativação de Scrt2 na medula espinhal embrionária de zebrafish causou aumento nos níveis de morte 
celular, sugerindo que os fatores Scrt também possuem atividade anti-apoptótica (RodríguezAznar, Nieto, 2011). De fato, a presença de fatores de sobrevivência é importante durante a transição do estado proliferativo para a diferenciação, visto que a perda das junções aderentes pode levar a uma consequente perda de sinais anti-apoptóticos ancorados a estas (Carmeliet et al., 1999). A diferenciação neural terminal se dá na periferia do tubo neural, ou zona do manto, onde ocorre, por exemplo, a neuritogênese. Fatores envolvidos neste último processo, como SCG10 (STMN2), uma proteína desestabilizadora de microtúbulos, e beta-tubulina neural III, uma tubulina específica de células neurais, são abundantemente expressos nos precursores em diferenciação terminal (Caccamo et al., 1989; Denoulet et al., 1986; Moody et al., 1989; Stein et al., 1988). Juntamente com HuC/D, uma proteína que se liga a RNA (Okano, Darnell; 1997; Wakamatsu, Weston; 1997), estes fatores são amplamente usados como marcadores de neurônios em diferenciação avançada.

O SNP se origina em grande parte da crista, mas também possui contribuições dos placóides, e diversos dos fatores citados acima também participam da formação de seus neurônios (Baker, Bronner-Fraser, 2001; Couly, Le Douarin; 1985; Ma et al., 1999). Os gânglios da raiz dorsal (GRDs), que contém os corpos celulares de neurônios aferentes do SNP na região truncal, se formam a partir da crista neural que parte da medula espinhal, ao passo que, em gânglios craniais, como o trigeminal, os neurônios se originam tanto de células neuroepiteliais do próprio placóide como de células da crista neural que colonizam estes locais (Butler, Bronner, 2014).

\subsection{A família Scratch de fatores de transcrição}

Os fatores Scrt foram descritos originalmente em Drosophila, onde scrt possui expressão pan-neural e seu mutante apresentou defeitos na formação dos olhos que causaram um fenótipo semelhante a uma arranhadura (scratch, em inglês). Este mesmo estudo analisou o fenótipo de mutantes superexpressando scrt, nos quais observou-se a formação de um número maior de neurônios (Roark et al., 1995). Na verdade, o ortólogo de scrt no nematódeo Caenoharbditis elegans (C. elegans), CES-1, já havia sido descrito anteriormente. Neste modelo animal, scrt/CES-1 também aumenta o número de neurônios quando expresso em excesso durante o desenvolvimento. Especificamente, CES-1 promove a 
sobrevivência das células-irmãs dos neurônios NSM e 12, que normalmente sofrem morte celular programada (Ellis, Horvitz, 1991).

Em vertebrados, a primeira caracterização do campo de expressão de Scrt durante o desenvolvimento foi feita em camundongo, mostrando que Scrt1 é expresso amplamente no sistema nervoso em desenvolvimento, incluindo cérebro, retina, medula espinhal e GRDs. A comparação em cortes do telencéfalo do padrão de expressão de Scrt1 com os marcadores de BrdU (bromodeoxiuridina), que marca células na fase $\mathrm{S}$ do ciclo mitótico, e beta-3-tubulina, que marca neurônios diferenciados, revelou complementaridade entres estes, sugerindo que Scrt1 é expresso apenas em células pós-mitóticas que ainda não atingiram a diferenciação tardia (Nakakura et al., 2001a). Em um novo trabalho realizado com embriões de camundongo, uma análise com hibridação in situ ampliou o conhecimento acerca dos locais onde há expressão de Scrt, ao mostrar que ambos os parálogos Scrt1 e Scrt2 são de fato fatores neuro-específicos expressos tanto no sistema nervoso do embrião quanto em sítios específicos do cérebro adulto. Na medula espinhal do embrião, Scrt1/2 não são expressos na região central do tubo, contribuindo com a noção de que são expressos apenas após o egresso do ciclo celular. De fato, sua expressão não coincide com a de PCNA (Proliferating Cell Nuclear Antigen), um antígeno específico de células mitoticamente ativas. Particularmente, Scrt2 parece estar ausente da região onde se formam os interneurônios V2, causando uma descontinuidade em seu campo de expressão (Marín, Nieto, 2006).

O primeiro ensaio funcional com Scrt em células de vertebrados foi realizado com linhagens em cultura e sugeriu que Scrt1 é capaz de promover a diferenciação neural de células P19 (Nakakura et al., 2001b). Trabalhos subsequentes analisaram a função de Scrt2 na medula espinhal de zebrafish e no córtex de camundongo. Os ensaios funcionais realizados em zebrafish revelaram que Scrt2 é importante para a sobrevivência e inibição do estado proliferativo em precursores neurais pós-mitóticos da medula espinhal. Nestes trabalhos, injeções com RNA antisenso para Scrt2 aumentaram a morte celular, tanto em células transfectadas quanto em células vizinhas, e induziram a proliferação ectópica de neurônios em diferenciação que expressam Islet1 e HuC/D, aparentemente por meio da ativação indireta de p57 (CDKN1C), um inibidor de quinases dependente de ciclina que impede o reinício do ciclo celular (Rodríguez-Aznar, Nieto, 2011; Rodríguez-Aznar et al., 2013). Os estudos realizados no córtex de camundongo não detectaram efeitos de Scrt1/2 sobre os níveis de 
morte celular e proliferação após sua superexpressão ou inibição por shRNAs (short hairpin RNAs). Contudo, estas interferências causaram defeitos na migração de progenitores neurais para as camadas corticais externas. Estes trabalhos apontaram E-caderina e RND2, uma proteína que se liga a GTP e regula a função de Ngn2 sobre a migração neural (Heng et al., 2008), como potenciais alvos da atividade repressora de Scrt2 (Itoh et al., 2013; Paul et al., 2014).

Os genes da família Scrt são relacionados evolutivamente aos genes da família Snail, com a qual formam a superfamília Snail de fatores de transcrição (Manzanares et al., 2001). Os membros desta superfamília codificam proteínas que possuem um domínio aminoterminal chamado SNAG (Snail-Gfi) formado por nove aminoácidos, presente também nas oncoproteínas Gfi (Growth Factor Independent), e quatro a seis domínios zinc-fingers do tipo $\mathrm{C}_{2} \mathrm{H}_{2}$ na sua porção terminal, responsáveis pela ligação ao DNA. Além disso, os fatores Scratch possuem um domínio homônimo exclusivo, não encontrado nos membros da família Snail (Fig. 2; Nieto, 2002). O domínio SNAG parece ser importante para a atividade de repressão e localização celular tanto nas proteínas Gfi quanto nas proteínas Snail (Batlle et al., 2000; Grimes et al., 1996; Hemavathy et al., 2000; Kataoka et al., 2000), porém um estudo realizado com células em cultura não foi capaz de confirmar sua importância para a atividade repressora de Scrt1 (Nakakura et al., 2001b). A importância do domínio SCRATCH é desconhecida, sendo possivelmente uma característica que confere aos fatores Scrt a propriedade de se ligar a parceiros específicos. Além de se ligar ao DNA, alguns trabalhos demonstraram também que os zinc-fingers possuem sinais de localização nuclear (Mingot et al., 2009; Nakakura et al., 2001a). Diversos estudos levantaram evidências de que os zinc-fingers de Snail e Scrt se ligam

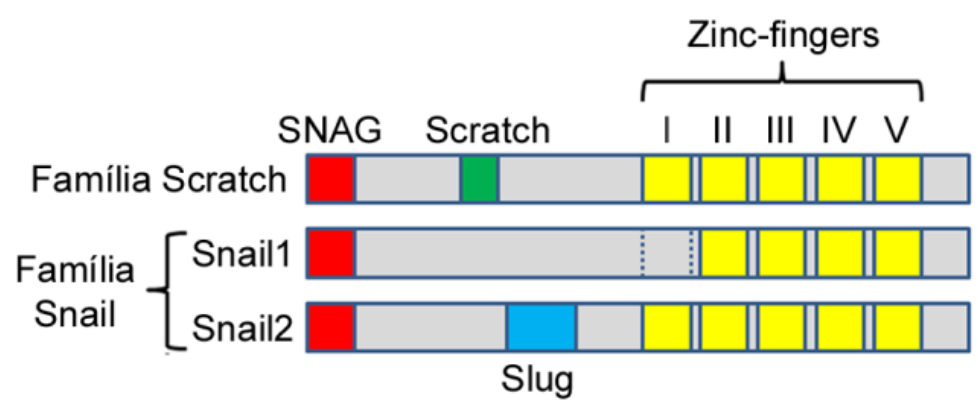

Figura 2. A superfamília Snail de fatores de transcrição. Os fatores de transcrição da superfamília Snail são divididos nas famílias Scratch e Snail e possuem um domínio SNAG na região N-terminal e quatro a seis zinc-fingers na região C-terminal, além de domínios exclusivos das proteínas Scratch e Snail2 (Slug). Retirado de Vieceli, 2009 baseado em Nieto, 2002. 
primariamente a sequências E-box (CANNTG) no DNA (Mauhin et al., 1993; Nakakura et al., 2001a; Paul et al., 2014; Rodríguez-Aznar, Nieto, 2011; Thellmann et al., 2003). No entanto, um estudo detalhado realizado com CES-1 sugeriu que, na verdade, a sequência preferencialmente reconhecida pelos fatores Scrt e Snail é uma versão modificada do E-box. Esta sequência, mais extensa que o E-box tradicional e apresentando variações preferenciais, foi chamada pelos autores de CES-box (CMACAGGTK) (Reece-Hoyes et al., 2009). Interessantemente, fatores bHLH, dos quais vários também são expressos durante 0 desenvolvimento precoce da medula espinhal (ver seção 1.1), também reconhecem sequências E-box, sugerindo que em algumas instâncias Scrt pode compartilhar alvos com fatores desta família. Interessantemente, fatores bHLH proneurais também regulam a saída do ciclo celular e a migração de precursores neurais (Garcia-Dominguez et al., 2003; Heng et al., 2008), o que, em conjunto com os dados obtidos para os fatores Scrt, sugere que a competição entre fatores Scrt e do tipo bHLH por elementos regulatórios que controlam alvos comuns pode ser importante para a regulação correta destes processos durante o desenvolvimento do sistema nervoso. De fato, invariavelmente os estudos que avaliaram uma possível interação entre Scrt e fatores bHLH sobre promotores potencialmente compartilhados encontraram evidências de que a presença de Scrt pode interferir com a atividade de fatores bHLH sobre alvos em comum (Nakakura et al., 2001a, 2001b; Paul et al., 2014; Reece-Hoyes et al., 2009; Roark et al., 1995). Por exemplo, Scrt1 foi capaz de reprimir a ativação de um promotor contendo múltiplos sítios E-box pelo fator bHLH Ash1 (AchaeteScute Homolog 1) e Scrt2 teve o mesmo efeito sobre um promotor ativado por Ngn2 também caracterizado pela presença de sequências E-box (Nakakura et al., 2001a; Paul et al., 2014). Ainda outras evidências desta interação foram obtidas em $C$. elegans, onde CES-1 compete com o heterodímero $\mathrm{HLH} 2 / \mathrm{HLH} 3$ para regular a transcrição do gene pró-apoptótico egl-1 (Thellmann et al., 2003). Interessantemente, no único caso reportado de um fator Scrt agindo como ativador, Reece-Hoyes e colaboradores identificaram que esta atividade é potencializada pela ação conjunta de HLH-6 (Reece-Hoyes et al., 2009). Em conclusão, existem alvos que são reprimidos por scrt/CES-1 e ativados por fatores bHLH e também alvos que podem ser ativados tanto por scrt/CES-1 quanto por fatores bHLH, sugerindo que a atuação de scrt/CES-1 depende de contexto celular. 


\subsection{Estudos de expressão diferencial com RNA-Seq}

O entendimento dos processos celulares que ocorrem durante o desenvolvimento passa pela identificação de fatores moleculares que caracterizam determinadas populações e pelo estudo de seus efeitos sobre a expressão de outros genes. Assim, tanto estudos descritivos quanto a análise de fenótipos causados pela manipulação gênica requerem o uso técnicas que permitam uma avaliação de níveis de expressão gênica. Técnicas clássicas, como imunomarcação e hibridação in situ, permitem a visualização de diferenças grandes na expressão de um gene/proteína candidato, conferindo informação espacial, mas não quantitativa (Acloque et al., 2008). Já o uso de qPCR permite a análise quantitativa de um número maior de genes com uma mesma amostra. Porém, este tipo de medição, obtida indiretamente com base na diferença do número de ciclos necessários para a amplificação de um gene em determinada amostra, está sujeita à adoção de critérios rigorosos para a obtenção de amostras e desenho de primers para garantir a sensibilidade do método (Pfaffl, 2001).

O uso de microarranjos, onde sondas para milhares de genes são distribuídas em um chip para a comparação de perfis de expressão em diferentes amostras, permitiu um enorme aumento na quantidade de informação que pode ser extraída de um único experimento (Olivera-Martínez et al., 2014). Neste tipo de experimento, a quantificação da expressão gênica é feita de forma relativa, onde o perfil do sinal fluorescente de uma amostra é comparado ao de outra. Isto significa, também, que a medição é indireta, uma vez que a quantidade de expressão de um determinado gene é derivada da intensidade de fluorescência emitida e não de um número absoluto de transcritos. Apesar de ter sido utilizada com bastante sucesso em várias publicações e projetos, esta tecnologia apresenta limitações inerentes. Primeiramente, por ser uma mensuração indireta por fluorescência, existe saturação do sinal para genes que são altamente expressos. Além disto, os dados provenientes de genes de baixa representatividade, ou seja, com níveis reduzidos de expressão, podem ser eliminados durante o processamento de redução de ruído do sinal. Além disso, o repertório de genes averiguados é limitado pelas sondas presentes no chip utilizado. Em outras palavras, a possibilidade de descoberta de genes novos ou isoformas resultantes de processamento alternativo é limitada com o uso de microarranjos (Marioni et al., 2008). 
Avanços tecnológicos recentes hoje permitem o sequenciamento rápido e simultâneo de centenas de milhões de moléculas de DNA a um custo bastante reduzido, também conhecido como sequenciamento de nova-geração. Esta tecnologia foi adaptada para estudos transcriptômicos com o desenvolvimento de técnicas para o sequenciamento indireto de RNA, conhecidas em conjunto como RNA-Seq (Cloonan et al., 2008; Mardis, 2008; Mortazavi et al., 2008; Nagalakshimi et al., 2008). Neste tipo de análise, dezenas de milhões de moléculas de uma amostra de cDNA são sequenciadas e, em seguida, as leituras obtidas são associadas a genes individuais, permitindo a obtenção de uma representação digital do transcriptoma. Em outras palavras, com RNA-Seq é possível observar a frequência de determinado transcrito em uma amostra sem a necessidade de qualquer normalização além da simples correção pelo número de total leituras obtidas em cada amostra. Em comparação aos microarranjos, a técnica de RNA-Seq tem se mostrado mais precisa em função das vantagens conferidas por sua natureza digital, e vem rapidamente substituindo o uso de microarranjos (Marioni et al., 2008). Além disso, com dados obtidos por RNA-Seq é possível detectar junções exon-exon, permitindo também a caracterização de isoformas (Trapnell et al., 2012).

No procedimento utilizado para a obtenção de dados por RNA-Seq na plataforma Illumina, a mais amplamente utilizada atualmente, o RNA primeiramente é extraído, fragmentado e convertido em cDNA (Wilhelm, Landry, 2009). Em seguida, o cDNA é ligado a adaptadores de DNA fixam as o cDNA por hibridação a um substrato sólido, onde se dará o sequenciamento. Para isto, o substrato é recoberto por pequenas moléculas de DNA com sequência complementar à dos adaptadores. Doravante, as moléculas imobilizadas são amplificadas por PCR para gerar agrupamentos de aproximadamente 1000 clones. Finalmente, os agrupamentos derivados de cada molécula imobilizada são sequenciados por síntese simultaneamente (Fig. 3A). A cada ciclo de incorporação de nucleotídeos durante o sequenciamento, uma câmera de alta resolução detecta o último nucleotídeo incorporado em cada agrupamento, identificado por sua fluorescência. Ao final, as imagens obtidas a cada ciclo são usadas para determinação da sequência de cada agrupamento, derivado originalmente de uma única molécula imobilizada (Fig. 3B; Mardis, 2008). Os instrumentos Illumina HiSeq podem de 100 a 200 milhões de sequências derivadas moléculas de DNA distintas em cada um dos 12 compartimentos da célula de sequenciamento. Esta quantidade de moléculas sequenciadas provê um número de leituras, ou profundidade de sequenciamento, bem maior 


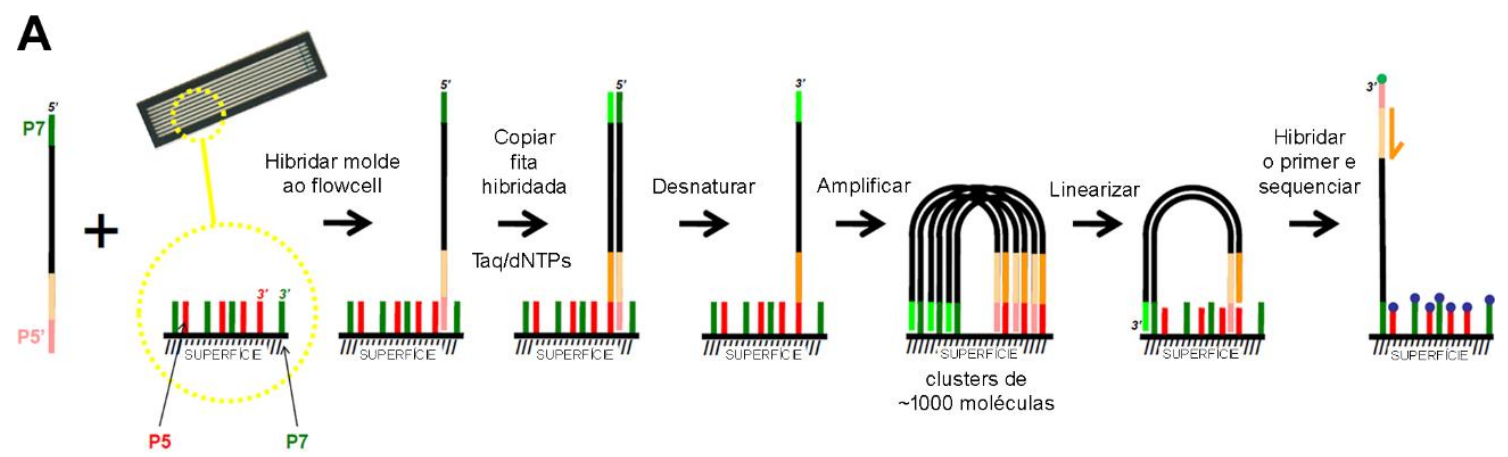

B

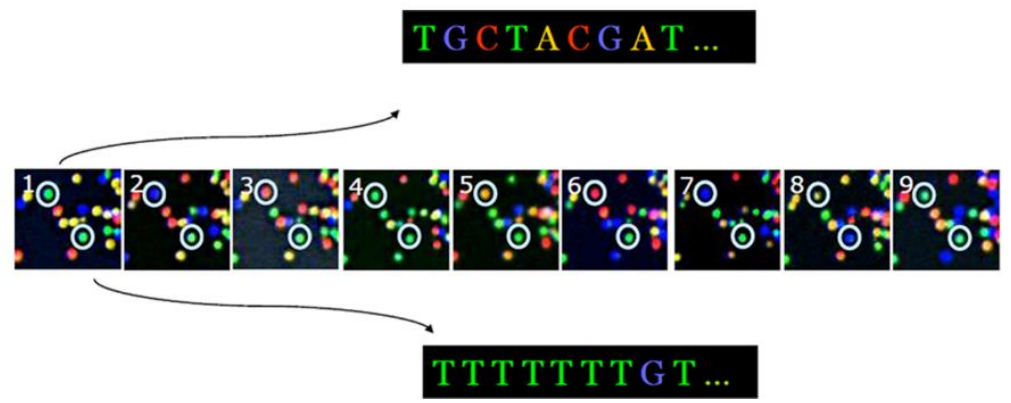

Figura 3. Sequenciamento na plataforma Illumina. (A) A biblioteca é hibridada ao substrato pela sequência P5 e uma cópia é sintetizada. Essa cópia é amplificada em pontes para formar clusters de $\mathbf{1 0 0 0}$ moléculas que em seguida são linearizadas em P5, hibridadas a um iniciador e sequenciadas. (B) A síntese na presença de nucleotídeos cuja fluorescência específica é detectada e removida a cada ciclo permite a determinação da sequência de cada molécula que hibridou e gerou um cluster na célula de sequenciamento. Adaptado de Harold Swerdlow (comunicação pessoal)¹.

do que o necessário para a obtenção de um transcriptoma com informação suficiente para determinar a expressão da maioria dos genes (Wang et al., 2011). Por esse motivo, na maioria das vezes amostras diferentes são marcadas com adaptadores que contêm códigos de barra de 6 nucleotídeos e então sequenciadas em um mesmo compartimento. Nestes casos, após uma análise inicial, os dados pertencentes a cada amostra podem ser separados pela identificação do código de barras presente em cada leitura.

Os dados de RNA-Seq são providos na forma de arquivos do tipo FASTQ, que possuem milhões de leituras derivadas de moléculas distintas e valores qualitativos associados a cada base sequenciada (Cock et al., 2010). Para a análise dos dados, os arquivos derivados de cada amostra são primeiramente processados para remover sequências-controle da plataforma, sequências com baixa qualidade e porções de sequências derivadas dos adaptadores

\footnotetext{
${ }^{1}$ Imagens apresentadas por Harold Swerdlow no curso Next-Generation Sequencing realizado em outubro de 2011 no Wellcome Trust Genome Campus em Hinxton, Reino Unido.
} 
(Blankenberg et al., 2010). Em seguida, as leituras são mapeadas por alinhamento ao genoma de referência. Finalmente, o mapeamento permite a montagem de um transcriptoma previsto e a associação de valores de níveis de expressão a cada gene identificado, o que, por sua vez, permite a comparação de amostras originárias de condições distintas para a identificação de genes diferencialmente expressos (Kim et al., 2013; Trapnell et al., 2010, 2012). 


\section{CAPÍTULO 5- CONCLUSÃO}

Neste trabalho nós caracterizamos em detalhe a expressão do fator de transcrição Scrt2 durante o desenvolvimento inicial da medula espinhal no embrião de galinha. Além disso, usamos formas alteradas de Scrt2 para estudar seus efeitos sobre o desenvolvimento inicial do tubo neural posterior. Além de analisar nossos experimentos com métodos de marcação para produtos de genes candidatos, realizamos também uma análise dos fenótipos resultantes com RNA-Seq, onde sequenciamento de DNA em larga escala é usado estimar níveis de expressão em uma amostra de RNA. Por fim, usamos RNA-Seq também para caracterizar o transcriptoma do tubo neural posterior em dois estádios de desenvolvimento, provendo uma base de dados qualitativos e quantitativos da expressão gênica durante a formação inicial da medula espinhal.

Nossos resultados mostraram que, como em outras espécies, também em galinha a expressão de Scrt2 é específica de tecidos neurais e está presente no tubo neural, GRDs e gânglios craniais em formação. No tubo neural, essa expressão está associada a populações pós-mitóticas em estádios iniciais de diferenciação neural. Além disso, mostramos que Scrt2 é expresso em conjunto com os fatores de transcrição bHLH Ngn2 e NeuroM. Considerando que fatores Scrt e bHLH competem por sítios E-box em alvos comuns, nossos resultados levantam a possibilidade de Scrt2 module a atividade de Ngn2 e NeuroM quando presentes na mesma célula. Em conjunto, os resultados obtidos contribuem para a ideia de que os fatores Scrt atuam no início da diferenciação neural.

A análise dos transcriptomas de tubos neurais eletroporados revelou apenas diferenças sutis em um pequeno número de genes. Acreditamos que isto se deu, principalmente, pela dificuldade de conseguir um alto nível de transfecção para todos os embriões usados, um problema comum em eletroporações do tubo neural já fechado. Assim, desencorajamos o uso de RNA-Seq para análise de experimentos com tecidos ou células que não podem ser transfectados com alta eficiência. Por outro lado, a comparação dos transcriptomas de tubos neurais em estádios distintos detectou diferenças significativas em até um terço dos genes, demonstrando a alta sensibilidade conseguida com o uso de RNASeq. Estes resultados não foram surpreendentes, visto que as amostras usadas eram 
compostas por células bastante distintas. Mesmo assim, procedimentos melhorados que permitam o uso de RNA-Seq com amostras reduzidas ou em condições onde as células comparadas possuem diferenças sutis são importantes, e muitos avanços foram feitos recentemente. Por exemplo, a purificação de células previamente à extração do RNA é uma solução possível para enriquecer a população desejada na amostra, mas este procedimento na maioria das vezes expõe o RNA à degradação. Além disso, novos métodos que permitem o sequenciamento de transcriptoma a partir de amostras muito pequenas ou células únicas foram descritos recentemente. Por exemplo, a aplicação deste tipo de procedimento em estudos com embriões de galinha pode eliminar a necessidade de que experimentos difíceis tenham que ser realizados com uma grande quantidade de indivíduos, tendo o potencial de viabilizar experimentos antes inviáveis.

Apesar de não termos detectado diferenças óbvias após manipular embriões com formas alteradas de Scrt2, usamos os dados obtidos com tubos neurais selvagens para investigar a expressão de outros fatores de transcrição no desenvolvimento inicial da medula espinhal. Verificamos em nossos dados uma grande lista de fatores de transcrição enriquecidos nos momentos iniciais da neurogênese e diferenciação neural, concordando com extensa reorganização da expressão gênica que acompanha este processo. Notamos também que a maior parte destes fatores inicialmente enriquecidos é reprimida com o progresso da diferenciação, sugerindo uma substituição intensa das proteínas que controlam a expressão gênica. Usamos nossos dados também para identificar potenciais novos fatores que regulam a diferenciação, para dois dos quais validamos os resultados com hibridações in situ. Assim, acreditamos que os dados que gerados em nossa análise têm um grande potencial de contribuir com novas informações acerca do desenvolvimento do sistema nervoso. 


\section{REFERÊNCIAS*}

Abranches E, Silva M, Pradier L, Schulz H, Hummel O, Henrique D, Bekman E. Neural differentiation of embryonic stem cells in vitro: a road map to neurogenesis in the embryo. PLoS One. 2009;4(7):e6286.

Acloque $\mathrm{H}$, Wilkinson DG, Nieto MA. In situ hybridization analysis of chick embryos in wholemount and tissue sections. Methods in Cell Biology. 2008;87:169-85.

Aubert J, Stavridis MP, Tweedie S, O'Reilly M, Vierlinger K, Li M, Ghazal P, Pratt T, Mason JO, Roy $D$, Smith A. Screening for mammalian neural genes via fluorescence-activated cell sorter purification of neural precursors from Sox1-gfp knock-in mice. Proceedings of the National Academy of Sciences of the United States of America. 2003;100(Suppl1):11836-41.

Avivi C, Goldstein RS. Differential expression of Islet-1 in neural crest-derived ganglia: Islet-1 + dorsal root ganglion cells are post-mitotic and Islet-1 + sympathetic ganglion cells are still cycling. Brain Research Developmental Brain Research. 1999;115(1):89-92.

Baker CV, Bronner-Fraser M. Vertebrate cranial placodes I. Embryonic induction. Developmental Biology. 2001;232(1):1-61.

Batlle E, Sancho E, Francí C, Domínguez D, Monfar M, Baulida J, García De Herreros A. The transcription factor snail is a repressor of E-cadherin gene expression in epithelial tumour cells. Nature Cell Biology. 2000;2(2):84-9.

Bertrand N, Castro DS, Guillemot F. Proneural genes and the specification of neural cell types. Nature Reviews Neuroscience. 2002;3(7):517-30.

Bierne $H$, Tham TN, Batsche E, Dumay A, Leguillou M, Kernéis-Golsteyn S, Regnault B, Seeler JS, Muchardt C, Feunteun J, Cossart P. Human BAHD1 promotes heterochromatic gene silencing. Proceedings of the National Academy of Sciences of the United States of America. 2009;106(33):13826-31.

Blankenberg D, Gordon A, Von Kuster G, Coraor N, Taylor J, Nekrutenko A; Galaxy Team. Manipulation of FASTQ data with Galaxy. Bioinformatics. 2010;26(14):1783-5.

Blentic A, Chambers D, Skinner A, Begbie J, Graham A. The formation of the cranial ganglia by placodally-derived sensory neuronal precursors. Molecular and Cellular Neurosciences. 2011;46(2):452-9.

\footnotetext{
* De acordo com International Committee of Medical Journal Editors. [Internet. Uniform requirements for manuscripts submitted to biomedical journals. [2013 Aug 20]. Available from: http://www.nlm.nih.gov/bsd/uniform_requirements.html
} 
Butler SJ, Bronner ME. From classical to current: Analyzing peripheral nervous system and spinal cord lineage and fate. Developmental Biology. 2014;S0012-1606(14)00529-6.

Bylund M, Andersson E, Novitch BG, Muhr J. Vertebrate neurogenesis is counteracted by Sox13 activity. Nature Neuroscience. 2003;6(11):1162-8.

Caccamo D, Katsetos CD, Herman MM, Frankfurter A, Collins VP, Rubinstein LJ. Immunohistochemistry of a spontaneous murine ovarian teratoma with neuroepithelial differentiation. Neuron-associated beta-tubulin as a marker for primitive neuroepithelium. Laboratory Investigation. 1989;60(3):390-8.

Campos-Ortega JA. Genetic mechanisms of early neurogenesis in Drosophila melanogaster. Molecular Neurobiology. 1995;10(2-3):75-89.

Cano A, Pérez-Moreno MA, Rodrigo I, Locascio A, Blanco MJ, del Barrio MG, Portillo F, Nieto MA. The transcription factor snail controls epithelial-mesenchymal transitions by repressing E-cadherin expression. Nature Cell Biology. 2000;2(2):76-83.

Carmeliet P, Lampugnani MG, Moons L, Breviario F, Compernolle V, Bono F, Balconi G, Spagnuolo R, Oosthuyse B, Dewerchin M, Zanetti A, Angellilo A, Mattot V, Nuyens D, Lutgens E, Clotman F, de Ruiter MC, Gittenberger-de Groot A, Poelmann R, Lupu F, Herbert JM, Collen $D$, Dejana E. Targeted deficiency or cytosolic truncation of the VE-cadherin gene in mice impairs VEGF-mediated endothelial survival and angiogenesis. Cell. 1999;98(2):147-57.

Castro DS, Skowronska-Krawczyk D, Armant O, Donaldson IJ, Parras C, Hunt C, Critchley JA, Nguyen L, Gossler A, Göttgens B, Matter JM, Guillemot F. Proneural bHLH and Brn proteins coregulate a neurogenic program through cooperative binding to a conserved DNA motif. Developmental Cell. 2006;11(6):831-44.

Cayouette M, Raff M. Asymmetric segregation of Numb: a mechanism for neural specification from Drosophila to mammals. Nature Neuroscience. 2002;5(12):1265-9.

Chasman DI, Leatherwood J, Carey M, Ptashne M, Kornberg RD. Activation of yeast polymerase II transcription by herpesvirus VP16 and GAL4 derivatives in vitro. Molecular and Cellular Biology. 1989;9(11):4746-9.

Chekmenev DS, Haid C, Kel AE. P-Match: transcription factor binding site search by combining patterns and weight matrices. Nucleic Acids Research. 2005;33:W432-7.

Chen J, Bardes EE, Aronow BJ, Jegga AG. ToppGene Suite for gene list enrichment analysis and candidate gene prioritization. Nucleic Acids Research. 2009;37:W305-11.

Cloonan N, Forrest AR, Kolle G, Gardiner BB, Faulkner GJ, Brown MK, Taylor DF, Steptoe AL, Wani S, Bethel G, Robertson AJ, Perkins AC, Bruce SJ, Lee CC, Ranade SS, Peckham HE, Manning JM, McKernan KJ, Grimmond SM. Stem cell transcriptome profiling via massive-scale mRNA sequencing. Nature Methods. 2008;5(7):613-9. 
Cock PJ, Fields CJ, Goto N, Heuer ML, Rice PM. The Sanger FASTQ file format for sequences with quality scores, and the Solexa/Illumina FASTQ variants. Nucleic Acids Research. 2010;38(6):1767-71.

Couly GF, Le Douarin NM. Mapping of the early neural primordium in quail-chick chimeras. I. Developmental relationships between placodes, facial ectoderm, and prosencephalon. Developmental Biology. 1985;110(2):422-39.

Cui S, Goldstein RS. Early markers of neuronal differentiation in DRG: islet-1 expression precedes that of Hu. Brain Research Developmental Brain Research. 2000;121(2):209-12.

Dady A, Blavet C, Duband JL. Timing and kinetics of $\mathrm{E}$ - to $\mathrm{N}$-cadherin switch during neurulation in the avian embryo. Developmental Dynamics. 2012;241(8):1333-49.

Dam TM, Kim HT, Moon HY, Hwang KS, Jeong YM, You KH, Lee JS, Kim CH. Neuron-specific expression of scratch genes during early zebrafish development. Molecules and Cells. 2011;31(5):471-5.

Darnell DK, Kaur S, Stanislaw S, Konieczka JH, Yatskievych TA, Antin PB. MicroRNA expression during chick embryo development. Developmental Dynamics. 2006;235(11):3156-65.

Denoulet P, Eddé B, Gros F. Differential expression of several neurospecific beta-tubulin mRNAs in the mouse brain during development. Gene. 1986;50(1-3):289-97.

Dessaud E, McMahon AP, Briscoe J. Pattern formation in the vertebrate neural tube: a sonic hedgehog morphogen-regulated transcriptional network. Development. 2008;135(15):2489503.

Diez del Corral R, Storey KG. Markers in vertebrate neurogenesis. Nature Reviews Neuroscience. 2001;2(11):835-9.

Dittmer S, Kovacs Z, Yuan SH, Siszler G, Kögl M, Summer H, Geerts A, Golz S, Shioda T, Methner A. TOX3 is a neuronal survival factor that induces transcription depending on the presence of CITED1 or phosphorylated CREB in the transcriptionally active complex. Journal of Cell Science. 2011;124(Pt 2):252-60.

Dykes IM, Tempest L, Lee SI, Turner EE. Brn3a and Islet1 act epistatically to regulate the gene expression program of sensory differentiation. The Journal of Neuroscience. 2011;31(27):9789-99.

Ellis RE, Horvitz HR. Two C. elegans genes control the programmed deaths of specific cells in the pharynx. Development. 1991;112(2):591-603.

Farkas LM, Huttner WB. The cell biology of neural stem and progenitor cells and its significance for their proliferation versus differentiation during mammalian brain development. Current Opinion in Cell Biology. 2008;20(6):707-15.

Gaiteri C, Ding Y, French B, Tseng GC, Sibille E. Beyond modules and hubs: the potential of gene coexpression networks for investigating molecular mechanisms of complex brain disorders. Genes, Brain and Behavior. 2014;13(1):13-24. 
Garcia-Dominguez M, Poquet C, Garel S, Charnay P. Ebf gene function is required for coupling neuronal differentiation and cell cycle exit. Development. 2003;130(24):6013-25.

George L, Kasemeier-Kulesa J, Nelson BR, Koyano-Nakagawa N, Lefcort F. Patterned assembly and neurogenesis in the chick dorsal root ganglion. The Journal of Comparative Neurology. 2010;518(4):405-22.

Gilbert SF. Developmental Biology. 9th ed. Sunderland: Sinauer; 2010. 711 p.

Goecks J, Nekrutenko A, Taylor J; Galaxy Team. Galaxy: a comprehensive approach for supporting accessible, reproducible, and transparent computational research in the life sciences. Genome Biology. 2010;11(8):R86.

Goff L, Trapnell C and Kelley D. cummeRbund: Analysis, exploration, manipulation, and visualization of Cufflinks high-throughput sequencing data. R package version 2.8.2., 2009. Software.

Grimes HL, Chan TO, Zweidler-McKay PA, Tong B, Tsichlis PN. The Gfi-1 proto-oncoprotein contains a novel transcriptional repressor domain, SNAG, and inhibits $\mathrm{G} 1$ arrest induced by interleukin-2 withdrawal. Molecular and Cellular Biology. 1996;16(11):6263-72.

Guillemot F. Spatial and temporal specification of neural fates by transcription factor codes. Development. 2007;134(21):3771-80.

Hamburger RV, Hamilton HL. A series of normal stages in the development of the chick embryo. Journal of Morphology. 1951;88(1):49-92.

Hemavathy K, Ashraf SI, Ip YT. Snail/slug family of repressors: slowly going into the fast lane of development and cancer. Gene. 2000;257(1):1-12.

Heng JI, Nguyen L, Castro DS, Zimmer C, Wildner H, Armant O, Skowronska-Krawczyk D, Bedogni F, Matter JM, Hevner R, Guillemot F. Neurogenin 2 controls cortical neuron migration through regulation of Rnd2. Nature. 2008;455(7209):114-8.

Henthorn $\mathrm{P}$, Kiledjian $\mathrm{M}$, Kadesch $\mathrm{T}$. Two distinct transcription factors that bind the immunoglobulin enhancer microE5/kappa 2 motif. Science. 1990;247(4941):467-70.

Hirata H, Yoshiura S, Ohtsuka T, Bessho Y, Harada T, Yoshikawa K, Kageyama R. Oscillatory expression of the bHLH factor Hes1 regulated by a negative feedback loop. Science. 2002;298(5594):840-3.

Hollyday M. Neurogenesis in the vertebrate neural tube. International Journal of Developmental Neuroscience. 2001;19(2):161-73.

Hollyday M, Hamburger V. An autoradiographic study of the formation of the lateral motor column in the chick embryo. Brain Research. 1977;132(2):197-208.

Honjo T. The shortest path from the surface to the nucleus: RBP-J kappa/Su(H) transcription factor. Genes to Cells. 1996;1(1):1-9. 
Hwang SG, Kim DS, Hwang JE, Han AR, Jang CS. Identification of rice genes associated with cosmic-ray response via co-expression gene network analysis. Gene. 2014;541(2):82-91.

Ichihara A, Greenberg DM. Pathway of serine formation from carbohydrate in rat liver. Proceedings of the National Academy of Sciences of the United States of America. 1955;41(9):605-9.

Itasaki N, Bel-Vialar S, Krumlauf R. 'Shocking' developments in chick embryology: electroporation and in ovo gene expression. Nature Cell Biology. 1999;1(8):E203-7.

Itoh Y, Moriyama Y, Hasegawa T, Endo TA, Toyoda T, Gotoh Y. Scratch regulates neuronal migration onset via an epithelial-mesenchymal transition-like mechanism. Nature Neuroscience. 2013;16(4):416-25.

Ivey DM, Guffanti AA, Zemsky J, Pinner E, Karpel R, Padan E, Schuldiner S, Krulwich TA. Cloning and characterization of a putative $\mathrm{Ca} 2+/ \mathrm{H}+$ antiporter gene from Escherichia coli upon functional complementation of $\mathrm{Na}+\mathrm{H}+$ antiporter-deficient strains by the overexpressed gene. The Journal of Biological Chemistry. 1993;268(15):11296-303.

Jacob J, Briscoe J. Gli proteins and the control of spinal-cord patterning. EMBO Reports. 2003;4(8):761-5.

Jacobson M. Developmental Neurobiology. 3rd ed. New York: Plenum Press; 1991. 776 p.

Jafar-Nejad H, Norga K, Bellen H. Numb: "Adapting" notch for endocytosis. Developmental Cell. 2002;3(2):155-6.

Jaynes JB, O'Farrell PH. Active repression of transcription by the engrailed homeodomain protein. The EMBO Journal. 1991;10(6):1427-33.

Johnson JE, Birren SJ, Anderson DJ. Two rat homologues of Drosophila achaete-scute specifically expressed in neuronal precursors. Nature. 1990;346(6287):858-61.

Jones JO, Chin SF, Wong-Taylor LA, Leaford D, Ponder BA, Caldas C, Maia AT. TOX3 mutations in breast cancer. PLoS One. 2013;8(9):e74102.

Kageyama R, Ohtsuka T, Kobayashi T. The Hes gene family: repressors and oscillators that orchestrate embryogenesis. Development. 2007;134(7):1243-51.

Kataoka H, Murayama T, Yokode M, Mori S, Sano H, Ozaki H, Yokota Y, Nishikawa S, Kita T. A novel snail-related transcription factor Smuc regulates basic helix-loop-helix transcription factor activities via specific E-box motifs. Nucleic Acids Research. 2000;28(2):626-33.

Kawakami Y, Yoshida K, Yang JH, Suzuki T, Azuma N, Sakai K, Hashikawa T, Watanabe M, Yasuda K, Kuhara S, Hirabayashi Y, Furuya S. Impaired neurogenesis in embryonic spinal cord of Phgdh knockout mice, a serine deficiency disorder model. Neuroscience Research. 2009;63(3):184-93. 
Kim D, Pertea G, Trapnell C, Pimentel H, Kelley R, Salzberg SL. TopHat2: accurate alignment of transcriptomes in the presence of insertions, deletions and gene fusions. Genome Biology. 2013;14(4):R36.

Knight RD, Shimeld SM. Identification of conserved $\mathrm{C} 2 \mathrm{H} 2$ zinc-finger gene families in the Bilateria. Genome Biology. 2001;2(5):RESEARCH0016.

Kumar A, Tikoo S, Maity S, Sengupta S, Sengupta S, Kaur A, Bachhawat AK. Mammalian proapoptotic factor $\mathrm{ChaC} 1$ and its homologues function as $\gamma$-glutamyl cyclotransferases acting specifically on glutathione. EMBO Reports. 2012;13(12):1095-101.

Lanier J, Quina LA, Eng SR, Cox E, Turner EE. Brn3a target gene recognition in embryonic sensory neurons. Developmental Biology. 2007;302(2):703-16.

Le Douarin N, Kalcheim C. The Neural Crest. 2nd ed. New York: Cambridge University Press; 2009. 472 p.

Le Dréau G, Martí E. The multiple activities of BMPs during spinal cord development. Cellular and Molecular Life Sciences. 2013;70(22):4293-305.

Lee JE, Hollenberg SM, Snider L, Turner DL, Lipnick N, Weintraub H. Conversion of Xenopus ectoderm into neurons by NeuroD, a basic helix-loop-helix protein. Science. 1995;268(5212):836-44.

Locasale JW, Grassian AR, Melman T, Lyssiotis CA, Mattaini KR, Bass AJ, Heffron G, Metallo CM, Muranen T, Sharfi H, Sasaki AT, Anastasiou D, Mullarky E, Vokes NI, Sasaki M, Beroukhim R, Stephanopoulos G, Ligon AH, Meyerson M, Richardson AL, Chin L, Wagner G, Asara JM, Brugge JS, Cantley LC, Vander Heiden MG. Phosphoglycerate dehydrogenase diverts glycolytic flux and contributes to oncogenesis. Nature Genetics. 2011;43(9):869-74.

Locascio A, Manzanares M, Blanco MJ, Nieto MA. Modularity and reshuffling of Snail and Slug expression during vertebrate evolution. Proceedings of the National Academy of Sciences of the United States of America. 2002;99(26):16841-6.

Ma Q, Fode C, Guillemot F, Anderson DJ. Neurogenin1 and neurogenin2 control two distinct waves of neurogenesis in developing dorsal root ganglia. Genes \& Development. 1999;13(13):1717-28.

Manzanares M, Locascio A, Nieto MA. The increasing complexity of the Snail gene superfamily in metazoan evolution. Trends in Genetics. 2001;17(4):178-81.

Mardis ER. Next-generation DNA sequencing methods. Annual Review of Genomics and Human Genetics. 2008;9:387-402.

Mariani M, Baldessari D, Francisconi S, Viggiano L, Rocchi M, Zappavigna V, Malgaretti N, Consalez GG. Two murine and human homologs of mab-21, a cell fate determination gene involved in Caenorhabditis elegans neural development. Human Molecular Genetics. 1999;8(13):2397-406. 
Marioni JC, Mason CE, Mane SM, Stephens M, Gilad Y. RNA-seq: an assessment of technical reproducibility and comparison with gene expression arrays. Genome Research. 2008;18(9):1509-17.

Marín F, Nieto MA. The expression of Scratch genes in the developing and adult brain. Developmental Dynamics. 2006;235(9):2586-91.

Mauhin V, Lutz Y, Dennefeld C, Alberga A. Definition of the DNA-binding site repertoire for the Drosophila transcription factor SNAIL. Nucleic Acids Research. 1993;21(17):3951-7.

McCabe KL, Sechrist JW, Bronner-Fraser M. Birth of ophthalmic trigeminal neurons initiates early in the placodal ectoderm. The Journal of Comparative Neurology. 2009;514(2):161-73.

Metzstein MM, Horvitz HR. The C. elegans cell death specification gene ces-1 encodes a snail family zinc finger protein. Molecular Cell. 1999;4(3):309-19.

Mi H, Muruganujan A, Casagrande JT, Thomas PD. Large-scale gene function analysis with the PANTHER classification system. Nature Protocols. 2013;8(8):1551-66.

Mingot JM, Vega S, Maestro B, Sanz JM, Nieto MA. Characterization of Snail nuclear import pathways as representatives of $\mathrm{C} 2 \mathrm{H} 2$ zinc finger transcription factors. Journal of Cell Science. 2009;122(Pt 9):1452-60.

Moody SA, Quigg MS, Frankfurter A. Development of the peripheral trigeminal system in the chick revealed by an isotype-specific anti-beta-tubulin monoclonal antibody. The Journal of Comparative Neurology. 1989;279(4):567-80.

Mortazavi A, Williams BA, McCue K, Schaeffer L, Wold B. Mapping and quantifying mammalian transcriptomes by RNA-Seq. Nature Methods. 2008;5(7):621-8.

Mungrue IN, Pagnon J, Kohannim O, Gargalovic PS, Lusis AJ. CHAC1/MGC4504 is a novel proapoptotic component of the unfolded protein response, downstream of the ATF4-ATF3CHOP cascade. Journal of Immunology. 2009;182(1):466-76.

Murre C, McCaw PS, Vaessin H, Caudy M, Jan LY, Jan YN, Cabrera CV, Buskin JN, Hauschka SD, Lassar $\mathrm{AB}$, et al. Interactions between heterologous helix-loop-helix proteins generate complexes that bind specifically to a common DNA sequence. Cell. 1989;58(3):537-44.

Nagalakshmi U, Wang Z, Waern K, Shou C, Raha D, Gerstein M, Snyder M. The transcriptional landscape of the yeast genome defined by RNA sequencing. Science. 2008;320(5881):1344-9.

Nakakura EK, Watkins DN, Schuebel KE, Sriuranpong V, Borges MW, Nelkin BD, Ball DW. Mammalian Scratch: a neural-specific Snail family transcriptional repressor. Proceedings of the National Academy of Sciences of the United States of America. 2001;98(7):4010-5.

Nakakura EK, Watkins DN, Sriuranpong V, Borges MW, Nelkin BD, Ball DW. Mammalian Scratch participates in neuronal differentiation in P19 embryonal carcinoma cells. Brain Research Molecular Brain Research. 2001b;95(1-2):162-6. 
Nieto MA. The snail superfamily of zinc-finger transcription factors. Nature Reviews Molecular Cell Biology. 2002;3(3):155-66.

Ohsawa R, Ohtsuka T, Kageyama R. Mash1 and Math3 are required for development of branchiomotor neurons and maintenance of neural progenitors. The Journal of Neuroscience. 2005;25(25):5857-65.

Ohtsuka T, Ishibashi M, Gradwohl G, Nakanishi S, Guillemot F, Kageyama R. Hes1 and Hes5 as notch effectors in mammalian neuronal differentiation. The EMBO Journal. 1999;18(8):2196207.

Okano HJ, Darnell RB. A hierarchy of Hu RNA binding proteins in developing and adult neurons. The Journal of Neuroscience. 1997;17(9):3024-37.

Olivera-Martinez I, Schurch N, Li RA, Song J, Halley PA, Das RM, Burt DW, Barton GJ, Storey KG. Major transcriptome re-organisation and abrupt changes in signalling, cell cycle and chromatin regulation at neural differentiation in vivo. Development. 2014;141(16):3266-76.

Ovcharenko I, Nobrega MA, Loots GG, Stubbs L. ECR Browser: a tool for visualizing and accessing data from comparisons of multiple vertebrate genomes. Nucleic Acids Research. 2004;32:W280-6.

Paul V, Tonchev AB, Henningfeld KA, Pavlakis E, Rust B, Pieler T, Stoykova A. Scratch2 modulates neurogenesis and cell migration through antagonism of bHLH proteins in the developing neocortex. Cerebral Cortex. 2014;24(3):754-72.

Pfaffl MW. A new mathematical model for relative quantification in real-time RT-PCR. Nucleic Acids Research. 2001;29(9):e45.

Politis PK, Rohrer H, Matsas R. Expression pattern of BM88 in the developing nervous system of the chick and mouse embryo. Gene Expression Patterns. 2007;7(1-2):165-77.

Powell LM, Jarman AP. Context dependence of proneural bHLH proteins. Current Opinion in Genetics \& Development. 2008;18(5):411-7.

Reece-Hoyes JS, Deplancke B, Barrasa MI, Hatzold J, Smit RB, Arda HE, Pope PA, Gaudet J, Conradt B, Walhout AJ. The C. elegans Snail homolog CES-1 can activate gene expression in vivo and share targets with bHLH transcription factors. Nucleic Acids Research. 2009;37(11):3689-98.

Roark M, Sturtevant MA, Emery J, Vaessin H, Grell E, Bier E. scratch, a pan-neural gene encoding a zinc finger protein related to snail, promotes neuronal development. Genes \& Development. 1995;9(19):2384-98.

Robasky K, Lewis NE, Church GM. The role of replicates for error mitigation in next-generation sequencing. Nature Reviews Genetics. 2014;15(1):56-62.

Rodríguez-Aznar E, Barrallo-Gimeno A, Nieto MA. Scratch2 prevents cell cycle re-entry by repressing miR-25 in postmitotic primary neurons. The Journal of Neuroscience. 2013;33(12):5095-105. 
Rodríguez-Aznar E, Nieto MA. Repression of Puma by scratch2 is required for neuronal survival during embryonic development. Cell Death and Differentiation. 2011;18(7):1196-207.

Rogers CD, Saxena A, Bronner ME. Sip1 mediates an E-cadherin-to-N-cadherin switch during cranial neural crest EMT. The Journal of Cell Biology. 2013 Dec 9;203(5):835-47.

Ross SE, Greenberg ME, Stiles CD. Basic helix-loop-helix factors in cortical development. Neuron. 2003;39(1):13-25.

Rousso DL, Pearson CA, Gaber ZB, Miquelajauregui A, Li S, Portera-Cailliau C, Morrisey EE, Novitch BG. Foxp-mediated suppression of $\mathrm{N}$-cadherin regulates neuroepithelial character and progenitor maintenance in the CNS. Neuron. 2012;74(2):314-30.

Roztocil T, Matter-Sadzinski L, Alliod C, Ballivet M, Matter JM. NeuroM, a neural helix-loophelix transcription factor, defines a new transition stage in neurogenesis. Development. 1997;124(17):3263-72.

Sauka-Spengler T, Barembaum M. Gain- and loss-of-function approaches in the chick embryo. Methods in Cell Biology. 2008;87:237-56.

Shimojo $\mathrm{H}$, Ohtsuka $\mathrm{T}$, Kageyama R. Oscillations in notch signaling regulate maintenance of neural progenitors. Neuron. 2008;58(1):52-64.

Simões-Costa M, Tan-Cabugao J, Antoshechkin I, Sauka-Spengler T, Bronner ME. Transcriptome analysis reveals novel players in the cranial neural crest gene regulatory network. Genome Research. 2014;24(2):281-90.

Stein R, Mori N, Matthews K, Lo LC, Anderson DJ. The NGF-inducible SCG10 mRNA encodes a novel membrane-bound protein present in growth cones and abundant in developing neurons. Neuron. 1988;1(6):463-76.

Stepniak E, Radice GL, Vasioukhin V. Adhesive and signaling functions of cadherins and catenins in vertebrate development. Cold Spring Harbor Perspectives in Biology. 2009;1(5):a002949.

Takebayashi K, Sasai Y, Sakai Y, Watanabe T, Nakanishi S, Kageyama R. Structure, chromosomal locus, and promoter analysis of the gene encoding the mouse helix-loop-helix factor HES-1. Negative autoregulation through the multiple $\mathrm{N}$ box elements. The Journal of Biological Chemistry. 1994;269(7):5150-6.

The Gene Ontology Consortium. Gene ontology: tool for the unification of biology. Nature Genetics. 2000;25(1):25-9.

Thellmann M, Hatzold J, Conradt B. The Snail-like CES-1 protein of C. elegans can block the expression of the $\mathrm{BH} 3$-only cell-death activator gene egl-1 by antagonizing the function of bHLH proteins. Development. 2003;130(17):4057-71.

Thiery JP, Delouvée A, Grumet M, Edelman GM. Initial appearance and regional distribution of the neuron-glia cell adhesion molecule in the chick embryo. The Journal of Cell Biology. $1985 ; 100(2): 442-56$. 
Trapnell C, Roberts A, Goff L, Pertea G, Kim D, Kelley DR, Pimentel H, Salzberg SL, Rinn JL, Pachter L. Differential gene and transcript expression analysis of RNA-seq experiments with TopHat and Cufflinks. Nature Protocols. 2012;7(3):562-78.

Trapnell C, Williams BA, Pertea G, Mortazavi A, Kwan G, van Baren MJ, Salzberg SL, Wold BJ, Pachter $\mathrm{L}$. Transcript assembly and quantification by RNA-Seq reveals unannotated transcripts and isoform switching during cell differentiation. Nature Biotechnology. 2010;28(5):511-5.

Vetter M. A turn of the helix: preventing the glial fate. Neuron. 2001;29(3):559-62.

Vieceli FM. Clonagem e análise da expressão do fator de transcrição Scratch2 durante a embriogênese inicial de galinha. [dissertação (Mestrado em Biologia Celular e Tecidual)]. São Paulo: Instituto de Ciências Biomédicas da Universidade de São Paulo; 2009.

Vieceli FM, Simões-Costa M, Turri JA, Kanno T, Bronner M, Yan CY. The transcription factor chicken Scratch2 is expressed in a subset of early postmitotic neural progenitors. Gene Expression Patterns. 2013;13(5-6):189-96.

Vieceli FM, Yan CY. RNA-Seq analysis of differential gene expression in electroporated chick embryonic spinal cord. Journal of Visualized Experiments. 2014;(93):e51951.

Viswanathan SR, Daley GQ. Lin28: A microRNA regulator with a macro role. Cell. 2010;140(4):445-9.

Wakamatsu Y, Weston JA. Sequential expression and role of Hu RNA-binding proteins during neurogenesis. Development. 1997;124(17):3449-60.

Wang Y, Ghaffari N, Johnson CD, Braga-Neto UM, Wang H, Chen R, Zhou H. Evaluation of the coverage and depth of transcriptome by RNA-Seq in chickens. BMC Bioinformatics. 2011;12(Suppl10):S5.

Wilhelm BT, Landry JR. RNA-Seq-quantitative measurement of expression through massively parallel RNA-sequencing. Methods. 2009;48(3):249-57.

Wu JQ, Habegger L, Noisa P, Szekely A, Qiu C, Hutchison S, Raha D, Egholm M, Lin H, Weissman $S$, Cui W, Gerstein M, Snyder M. Dynamic transcriptomes during neural differentiation of human embryonic stem cells revealed by short, long, and paired-end sequencing. Proceedings of the National Academy of Sciences of the United States of America. 2010;107(11):5254-9.

Zhang J, Woodhead GJ, Swaminathan SK, Noles SR, McQuinn ER, Pisarek AJ, Stocker AM, Mutch CA, Funatsu N, Chenn A. Cortical neural precursors inhibit their own differentiation via $\mathrm{N}$-cadherin maintenance of beta-catenin signaling. Developmental Cell. 2010;18(3):472-9. 